\title{
Predictive value of synovial fluid analysis in estimating the efficacy of intra-articular corticosteroid injections in patients with rheumatoid arthritis
}

Reijo Luukkainen, Markku Hakala, Esko Sajanti, Heini Huhtala, Urpo Yli-Kerttula, Risto Hämeenkorpi

\begin{abstract}
The predictive relevance of synovial fluid analysis and some other variables for the efficacy of intra-articular corticosteroid injections in 30 patients with rheumatoid arthritis and hydropsy in a knee joint was evaluated in a prospective study. At the onset of the study, the knee joints were aspirated and $30 \mathrm{mg}$ triamcinolone hexacetonide injected intra-articularly. The circumferences and the tenderness scores of the knee joints were measured at onset, after two months, and at the end of the six months' follow up. Of the variables studied, synovial fluid $\mathrm{C} 4$, percentage of synovial fluid polymorphonuclear leucocytes, blood haemoglobin, and serum C3 correlated significantly with the decrease in knee joint circumference after two months, whereas only the percentage of synovial fluid polymorphonuclear leucocytes correlated significantly after six months. Between the patients with and without improvement in the tenderness scores of the knee joints, only serum IgM differed at the examination after two months; this was higher in patients whose scores showed no improvement.
\end{abstract}

(Ann Rheum Dis 1992; 51: 874-876)

Department of Rheumatology, Satalinna Hospital, SF-29230 Satalinna, Finland

R Luukkainen

Department of Medicine,

Päivärinne Hospital, SF-91410 Jokirinne,

Finland

M Hakala

E Sajanti

R Hämeenkorpi

Department of

Public Health

University of Tampere,

SF-33101 Tampere,

Finland

H Huhtala

Department of Medicine,

Tampere University

Central Hospital,

SF-36280 Pikonlinna,

Finland

U Yli-Kerttula

Correspondence to:

Dr Reijo Luukkainen

Kreetalankatu $5 \mathrm{C}$

SF-29200 Harjavalta,

Finland.

Accepted for publication

26 November 1991
Pain and swelling in joints is a fundamental feature of rheumatoid arthritis (RA), while at the same time the amount of synovial fluid is often increased. Synovial fluid analysis is commonly used to diagnose arthritis and to evaluate the inflammatory activity of joint effusions. It may also be of help in predicting the outcome of joint inflammation. ${ }^{\prime}$ The inflamed joints are usually injected with corticosteroids at the time of aspiration. As the content of synovial fluid is known to reflect the pathological processes in the joint, it might have some prognostic value in estimating the efficacy of intra-articular corticosteroid injections. There have been no previous studies of synovial fluid analysis in this respect. The purpose of this prospective study was to evaluate the predictive value of synovial fluid analysis and other variables to the efficacy of corticosteroid injections into the knee joints of patients with RA.

\section{Patients and methods}

Thirty consecutive patients with $\mathrm{RA}^{2}$ and hydropsy in a knee joint fulfilling the following criteria were included in the study: age $20-70$ years; treatment with disease modifying drugs and corticosteroids by mouth stabilised during the previous three months and no intention to change the drug regimen; the largest allowed dose of corticosteroids by mouth equivalent to $7.5 \mathrm{mg}$ prednisolone; and an indication for intra-articular corticosteroid injections. If treatment with disease modifying drugs or corticosteroids by mouth changed during the follow up period of six months, the patient was removed from the study. Table 1 gives the drugs the patients were treated with during follow up. Nineteen of the patients received one to five (mean $2 \cdot 2$ ) intra-articular injections into some other joint during the follow up. The age range of the patients was 35-69 years (mean 52 years), the duration of RA was 1-37 years (mean 14 years), and the duration of arthritis of the knee joints was $0.3-37$ years (mean 8.8 years). Twenty of the patients were women and 25 were seropositive. Twenty six of the examined knee joints had previously been injected with long acting corticosteroids; the time between the last injection and the present examination was $1-38$ months (mean nine months).

At the start of the study the general activity of RA was assessed using the Ritchie articular index ${ }^{3}$ and the duration of morning stiffness, whereas the clinical inflammatory activity of the knee joint was evaluated using the activity index obtained from the sum of swelling and tenderness scores. These two scores were assessed as follows: nil $=0$, mild $=1$, moderate $=2$ and severe $=3$. The knee joints were radiographed at the start of the study and the grade of radiological destruction evaluated using Larsen's indices. ${ }^{4}$ The range of these indices was 0-3 (mean 1.5). The circumferences of the knee joints were measured in centimetres and the mean at the start was $41 \cdot 3$, after two months $39 \cdot 5$, and after six months $40 \cdot 1 \mathrm{~cm}$.

The knee joints were aspirated and injected

Table 1 Drugs used to treat the 30 patients with rheumatoid arthritis during the follow up period

\begin{tabular}{lc}
\hline Drug & No of patients \\
\hline Disease modifying drugs & 25 \\
Sulphasalazine & 8 \\
Sodium aurothiomalate & 6 \\
D-Penicillamine & 3 \\
Chloroquine & 3 \\
Auranofin & 2 \\
Azathioprine & 1 \\
Methotrexate & 1 \\
Sodium aurothiomalate+ chloroquine & 1 \\
Corticosteroids (by mouth) & 12 \\
Non-steroidal anti-inflammatory drugs & 29
\end{tabular}


with $30 \mathrm{mg}$ triamcinolone hexacetonide (Lederspan). The following variables were determined in the synovial fluid: leucocytes, percentage of polymorphonuclear leucocytes, proteins, acid phosphatase, lactate, glucose, C3, C4, IgA, IgG, IgM, rheumatoid factor (measured by the immunoturbidimetric method, Orion Diagnostica), viscosity, and mucine clot of synovial fluid. Blood haemoglobin, blood erythrocyte sedimentation rate, serum $C$ reactive protein, C3, C4, IgA, IgG, IgM, and rheumatoid factor (measured by the immunoturbidimetric method, Orion Diagnostica) were also determined. The laboratory tests were carried out using standard methods. Table 2 shows the blood, serum, and synovial fluid variables of the patients.

The patients were re-examined after two and six months, and the circumferences of all the knee joints were measured. The tenderness scores of the knee joints were assessed only in 28 patients at two months and in 26 patients at six months after the start of the study. If the knee joint in question needed an intra-articular corticosteroid injection during the follow up, the circumference and the tenderness score at the time of injection was considered to be that at the end of follow up. Three patients received such an injection, two after two months and one after four months from the start of the study.

Possible correlations of the continuous variables (age, duration of RA and arthritis in the knee joint, Ritchie index, morning stiffness, blood variables, serum variables, and synovial fluid variables) to the decrease in knee joint circumference after two and six months were calculated using Pearson's correlation coefficient.

Table 2 Blood, serum, and synovial fluid variables of the patients

\begin{tabular}{|c|c|}
\hline Variable & Mean $(S D)$ \\
\hline Blood ESR $(\mathrm{mm} / \mathrm{h})^{:}$ & $45 \cdot 5(25 \cdot 1)$ \\
\hline Blood haemoglobin $(\mathrm{g} / \mathrm{l})$ & $115 \cdot 3(12 \cdot 7)$ \\
\hline Serum CRP $(\mathbf{m g} / \mathbf{l})^{*}$ & $34 \cdot 1(24 \cdot 7)$ \\
\hline Serum C3 $(\mathrm{g} / \mathrm{l})$ & $1.01(0.29)$ \\
\hline Serum C4 $(\mathrm{g} / \mathrm{l})$ & $0.34(0 \cdot 17)$ \\
\hline Serum IgA $(g / 1)$ & $3.0(1.6)$ \\
\hline Serum IgG $(g / \mathbf{l})$ & $13 \cdot 5(3.4)$ \\
\hline Serum IgM $(g / \mathbf{l})$ & $1 \cdot 2(0 \cdot 6)$ \\
\hline Serum rheumatoid factor $(\mathrm{IU} / \mathrm{ml})$ & $194.5(316.0)$ \\
\hline Synovial fluid leucocytes $\left(\times 10^{9} / 1\right)$ & $8.9(6.6)$ \\
\hline \multicolumn{2}{|l|}{ Synovial fluid polymorphonuclear } \\
\hline leucocytes $(\%)$ & $54 \cdot 8(26 \cdot 4)$ \\
\hline Synovial fluid proteins $(\mathrm{g} / \mathrm{l})$ & $43 \cdot 0(9 \cdot 3)$ \\
\hline Synovial fluid acid phosphatase (IU/I) & $10 \cdot 4(8 \cdot 7)$ \\
\hline Synovial fluid lactate $(\mathrm{mmol} / \mathrm{l})$ & $3 \cdot 6(2 \cdot 4)$ \\
\hline Synovial fluid glucose $(\mathrm{mmol} / \mathrm{l})$ & $5 \cdot 6(8 \cdot 3)$ \\
\hline Synovial fluid $\mathrm{C} 3(\mathrm{~g} / \mathrm{I})$ & $0.38(0.12)$ \\
\hline Synovial fluid C4 (g/l) & $0.12(0.18)$ \\
\hline Synovial fluid IgA (g/l) & $1 \cdot 8(1 \cdot 2)$ \\
\hline Synovial fluid IgG (g/l) & $8 \cdot 7(3 \cdot 4)$ \\
\hline Synovial fluid IgM $(g / \mathbf{l})$ & $0.7(0.3)$ \\
\hline Synovial fluid rheumatoid factor $(\mathrm{IU} / \mathrm{ml})$ & $188 \cdot 0(256 \cdot 3)$ \\
\hline
\end{tabular}

Table 3 Significant coefficients of correlation between the variables and the decrease in knee joint circumference

\begin{tabular}{|c|c|c|c|c|}
\hline \multirow[t]{2}{*}{ Variable } & \multicolumn{2}{|c|}{2 Months } & \multicolumn{2}{|c|}{6 Months } \\
\hline & $r$ & $p$ Value & $r$ & D V'alue \\
\hline $\begin{array}{l}\text { Synovial fluid C4 } \\
\text { Synovial fluid polymorphonuclear }\end{array}$ & 0.51 & 0.003 & $0 \cdot 22$ & NS \\
\hline $\begin{array}{l}\text { leucocytes }(\%) \\
\text { Blood haemoglobin } \\
\text { Serum C3 }\end{array}$ & $\begin{array}{r}0 \cdot 37 \\
-0 \cdot 34 \\
0 \cdot 33\end{array}$ & $\begin{array}{l}0.027 \\
0.038 \\
0.043\end{array}$ & $\begin{array}{r}0.37 \\
-0.19 \\
0.23\end{array}$ & $\begin{array}{l}0.024 \\
\text { NS } \\
\text { NS }\end{array}$ \\
\hline
\end{tabular}

Cross tabulation was used to evaluate the relationship between the discrete variables (disease modifying drugs, intra-articular corticosteroid injections into other joints, Larsen's index, mucine clot of synovial fluid, and activity index of the knee joints) and the decrease in knee joint circumference. For this purpose the patients were divided into two groups according to whether or not the knee joint circumference had decreased by more than $1 \mathrm{~cm}$. At the examination after two months the decrease was more than $1 \mathrm{~cm}$ in 16 patients and after six months in 10 patients.

For the assessment of the predictive value of the variables to the tenderness score of the knees the patients were divided into two groups according to whether or not the tenderness score was improved during follow up. After two months it had improved in 17 patients and after six months in nine patients. The continuous variables between the improved patients and those who had not were compared by Student's $t$ test, whereas the discrete variables were calculated by cross tabulation.

\section{Results}

Table 3 gives the significant correlations between the continuous variables and the decrease in circumferences of the knee joints after two and six months. Synovial fluid C4 showed the best correlation after two months; the correlation coefficient was 0.51 , which differs significantly $(p=0.003)$ from zero. Of the remaining variables, the percentage of synovial fluid polymorphonuclear leucocytes, blood haemoglobin, and serum C3 showed significant correlations. After six months only the percentage of synovial fluid polymorphonuclear leucocytes $(r=0.37, p=0.024)$ correlated significantly in this respect.

There were no significant differences in the discrete variables between the patients with a decrease of knee joint circumference of more than $1 \mathrm{~cm}$ and those with a lower decrease.

In patients with an improvement in the tenderness score in knee joints the mean value of serum $\operatorname{IgM}$ was $1.0 \mathrm{~g} / \mathrm{l}$ after two months and in patients with no improvement $1.55 \mathrm{~g} / \mathrm{l}$. This difference was statistically significantly $(p=0.03)$ between the groups. Other variables did not differ significantly between these groups

\section{Discussion}

Although intra-articular corticosteroid injections are commonly used in the treatment of RA, little is known of the factors predicting the response to this treatment. In routine clinical work excellent results are obtained in some patients, whereas in others the response may be poor. Of the intra-articular corticosteroid drugs available, triamcinolone hexacetonide has the longest duration of suppression of inflammation and can be over one year at best. ${ }^{5}$ As intraarticular corticosteroid injections may cause side effects ${ }^{6}$ and some patients are reluctant to receive injections, it would be useful to find factors which could predict the effect of this treatment. 
In patients with RA serum complement is generally higher than normal values. ${ }^{7}$ Normal synovial fluid has been characterised as a dialysate of plasma, and synovial fluid proteins are mainly derived from plasma proteins and are approximately one third of the plasma concentrations. ${ }^{8}$ Synovial inflammation has been shown to be accompanied by the augmented passage of proteins across the synovial membrane. 9 In addition to this, local synthesis of immunoglobulins and complement proteins takes place in rheumatoid synovium. ${ }^{10} 11$ Thus in inflammatory synovial fluids the concentration of proteins increases. In synovial fluid from patients with RA, however, complement is generally lower than normal, which possibly results from the activation of the complement system by intra-articular antigen-antibody complexes. ${ }^{12}$ In our study the concentrations of immunoglobulins were about two thirds and those of complement about one third of their serum concentrations.

In patients with high grade local synovitis intra-articular corticosteroids may be especially effective because of their numerous anti-inflammatory effects. ${ }^{13}$ In this study synovial fluid C4 concentration had the best correlation with the decrease in knee joint circumference after two months. This may reflect a greater influx and increased local synthesis of $\mathrm{C} 4$ in patients with active synovitis. The percentage of synovial fluid polymorphonuclear leucocytes showed the second best correlation to a good result after two months.

A high percentage of synovial fluid polymorphonuclear leucocytes reflects the grade of inflammatory activity in a joint, which may be depressed by corticosteroids. ${ }^{14}$ The correlations of blood haemoglobin and serum $\mathrm{C} 4$ to the decrease in knee joint circumference after two months were rather low, even if they reached statistical significance. These findings are also possibly connected with the activity of synovitis, though neither other variables indicating the general activity of RA nor the activity index indicating clinical inflammatory activity in the knee joint in question showed any correlation in this respect.

Only serum IgM differed significantly between patient groups with an improvement in the tenderness scores of the knee joints and those without, and even this may be due to chance. There is therefore a conflict between the results of the knee joint circumferences and tenderness scores in our study in this respect. This may be partly explained by the fact that there are many tendon insertions and bursae around the knee joint. Hence possible insertitides and bursitides may confuse the evaluation of knee joint tenderness, though not the measurement of circumference. In addition to this, the tenderness and swelling may reflect different aspects of joint inflammation. This is supported by the work of Rhind $e t a l,{ }^{15}$ who found no correlation between the circumferences of the proximal interphalangeal joints of the fingers and Ritchie articular indices.

The finding that after six months the percentage of synovial fluid polymorphonuclear leucocytes correlated significantly with the decrease in knee joint circumference may have some clinical significance.

It is interesting to note that the duration of $\mathrm{RA}$, duration of arthritis in the joint in question, and Larsen's index had no predictive value in estimating the response to intra-articular corticosteroids. Hence joints with a longer duration of arthritis and with some destruction can also be successfully treated with intraarticular corticosteroids. The variables reflecting general activity of RA such as blood erythrocyte sedimentation rate, serum $C$ reactive protein, joint stiffness, and Ritchie index did not correlate significantly to the efficacy of corticosteroids.

The predictive value of synovial fluid analysis with respect to the efficacy of intra-articular corticosteroid injections in RA seems to be low. Only a high percentage of synovial fluid polymorphonuclear leucocytes relates to better results after six months. The number of patients in our study was small, and these results must be regarded as preliminary.

1 Luukkainen R, Kaarela K, Huhtala $\mathrm{H}$, et al. Prognostic significance of synovial fluid analysis in rheumatoid arthritis. Ann Med 1989; 21: 269-71.

2 Arnett F C, Edworthy S M, Bloch D A, et al. The American Rheumatism Association 1987 revised criteria for the classification of rheumatoid arthritis. Arthritis Rheum 1988; 31: $315-24$

3 Ritchie D M, Boyle J A, McInnes J M, et al. Clinical studies with an articular index for the assessment of joint tenderness in patients with rheumatoid arthritis. $Q \mathcal{F}$ Med 1968; 37: 393-406.

4 Larsen A, Dale K, Eek M. Radiographic evaluation of rheumatoid arthritis and related conditions by standard reference films. Acta Radiol Diagn 1977; 18: 481-91.

5 McCarty D J. Treatment of rheumatoid joint inflammation with triamcinolone hexacetonide. Arthritis Rheum 1972; 15: 157-73.

6 Gatter R A. Arthrocentesis technique and intrasynovial therapy. In: McCarty D J, ed. Arthritis and allied conditions. A textbook of rheumatology. 11th ed. Philadelphia: Lea \& Febiger, 1989: 646-56.

7 Vaughan J H, Bayles T B, Favour C B. Serum complement in rheumatoid arthritis. Am f Med Sci 1951; 222: 186-92.

8 Vernon-Roberts B. Synovial fluid and its examination. In: Scott J T, ed. Copeman's textbook of the rheumatic diseases. 6th ed. Edinburgh: Churchill Livingstone, 1986: 251-77.

9 Kushner I, Somerville J A. Permeability of human synovial membrane to plasma proteins. Relationship to molecular membrane to plasma proteins. Relationship to molecular

10 Smiley D J, Sachs C, Ziff M. In vitro synthesis of immunoglobulin by rheuamtoid synovial membrane. $\mathcal{F}$ Clin Invest 1968; 47: 624-32.

11 Ruddy S, Colten H R. Rheumatoid arthritis. Biosynthesis of complement proteins by synovial tissues. $N$ Engl 7 Med 1974; 290: 1284-8.

12 Bunch T W, Hunder G G, Duffie F C, et al. Synovial fluid complement determinations as a diagnostic aid in inflam matory joint disease. Mavo Clin Proc 1974; 49: 715-20.

13 Behrens T W, Goodwin J S. Glucocorticoids. In: McCarty $\mathrm{D} \mathrm{J}$, ed. Arthritis and allied conditions. A textbook of rheumatologv. 11 th ed. Philadelphia: Lea \& Febiger, 1989: 604-21.

4 Farr M, Kendall M J, Young D W, et al. Assessment of rheumatoid activity based on clinical features and blood and synovial fluid analysis. Ann Rheum Dis 1976; 35: and -7 .

15 Rhind V M, Bird H A, Wright V. A comparison of clinical assessment of disease activity in rheumatoid arthritis. Ann Rheum Dis 1980; 39: 135-7. 